\title{
Seasonal Variations of Wind Driven Mixing off Port Said, Egypt
}

\author{
Sayed Sharaf El-Din ${ }^{1}$, Mohamed Elsharkawy ${ }^{2}$ \\ ${ }^{1}$ University of Alexandria, Faculty of Science, Department of Oceanography, Alexandria, Egypt \\ ${ }^{2}$ National Institute of Oceanography and Fisheries, Physical Laboratory, Alexandria, Egypt \\ Email address: \\ ecosalex@hotmail.com (S. S. El-Din), sharkawy70@gmail.com (M. Elsharkawy)
}

\section{To cite this article:}

Sayed Sharaf El-Din, Mohamed Elsharkawy. Seasonal Variations of Wind Driven Mixing off Port Said, Egypt. Journal of Water Resources and Ocean Science. Vol. 4, No. 4, 2015, pp. 54-58. doi: 10.11648/j.wros.20150404.11

\begin{abstract}
The wind contribution to the process of vertical mixing in the near surface oceanic layers is empirically, estimated at a deep station $(500 \mathrm{~m})$ off Port Said, Egypt. The dimensional less parameter $R u$ which scales wind contribution is greatest during summer with values as high as 0.6. Calculations show that wind stress over the sea surface generally has a significant role in the dynamical process of vertical turbulent mixing except during winter.
\end{abstract}

Keywords: Vertical Mixing, Wind Stress, Wind Driven Mixing

\section{Introduction}

Tidal currents and atmospheric forcing over the upper sea surface are major producers of vertical turbulent mixing. The lunar semi-diurnal tide (M2) is estimated to produce about $2.5 \mathrm{TW}$ which is mostly dissipated by bottom friction in the boundaries of the water basins. The dynamical process of vertical turbulent mixing in coastal regions and continental slopes is strengthened by dissipation of tidal energy [1]. The wind driven mixing energy is estimated to be only $1 \mathrm{TW}$. The equator to pole heat flux, about 2000 $\mathrm{TW}$, together with continuous processes of upwelling and down welling maintain the equilibrium in the water basin [2].

Numerous coupled atmosphere - ocean models have been implemented to study the impact of barotropic tides in the North Atlantic Ocean. The surface density and salinity are predicted to increase by the effect of barotropic tides [3]. Surface wave breaking is an important source of shear production of turbulent kinetic energy. Momentum and energy transport across the air - sea interface also affect the distribution of viscous dissipation. These physical parameters have been used successfully to model wave enhanced turbulence in the upper sea layer [4]. This model has also been applied to study mixing rate and its dependence on buoyancy, turbulence, shear and dissipation off the Eastern Egyptian Mediterranean Coast [5].

Mixing parameters, as diffusive flux of salt, and momentum, off Port Sudan, Red Sea have been computed. The study showed that their magnitudes decrease with depth and that the water column tends to be more stable at deeper layers [6]. The analysis of the turbulent structure off the Eastern Egyptian Mediterranean Coast showed that instability occurs intermittently along the water column. The dynamical instability associated with negative values of squared buoyancy frequency occurred in the upper layers. Also, the study showed that Reynolds stress was greatest during winter [7].

In this study, the contribution of wind stress over the sea surface in the dynamical process of vertical mixing production was investigated. Seasonal variations of the nondimensional parameter $R u$ were analyzed to compare between tidal driven and wind driven mixing in the water column.

\section{Data Availabilty}

A series of daily records of wind and current field have been taken at an offshore fixed station off Port Said, Egypt with a geographic location (31.99 N, 32.07 E), and depth 500 m. Wind data was collected by a floating Anderra weather station, while the surface current was measured by a moored acoustic Doppler current profiler. The atmospheric-oceanic parameters were collected at time intervals corresponding to the four annual seasons. Information about the available data set is presented in table 1 . 
Table 1. Information about available data set.

\begin{tabular}{lllll}
\hline & Spring & Summer & Autumn & Winter \\
\hline Start date & $21 / 3 / 99$ & $21 / 6 / 99$ & $8 / 10 / 99$ & $6 / 1 / 99$ \\
End date & $17 / 5 / 99$ & $19 / 7 / 99$ & $28 / 11 / 99$ & $21 / 1 / 99$ \\
No. of records & 58 & 29 & 52 & 16 \\
\hline
\end{tabular}

\section{Estimates of Wind Stress}

The zonal component of wind stress $\tau_{x}$, and the meridional component of wind stress $\tau_{y}$, are related to their corresponding components of wind speed $V_{x}$ and $V_{y}$ respectively by the formula:

$$
\tau_{x}=\rho_{a} C_{D} V_{x} ; \tau_{y}=\rho_{a} C_{D} V_{y}
$$

where $\rho_{a}$ is the air density $\left(1.024 \mathrm{~kg} \mathrm{~m}^{-3}\right), C_{D}$ is the drag coefficient defined in terms of the magnitude of the wind speed $W$ as in $[8,9]$ :

$$
C_{D}=(0.75+0.067 W) \times 10^{-3}
$$

Temporal distribution of wind stress over the sea surface is shown in figures (1-4)

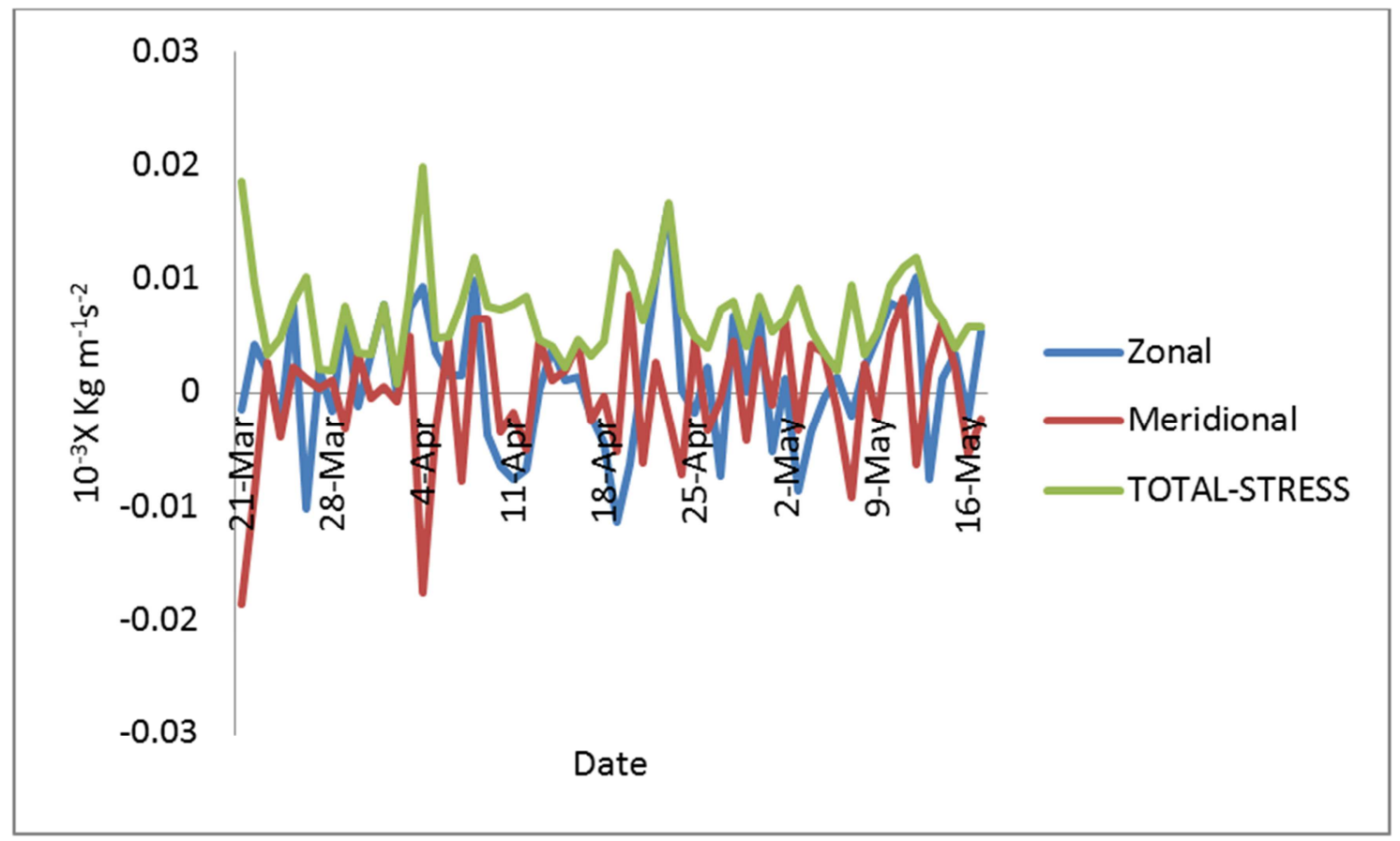

Fig. 1. Time series of wind stress components during spring survey.

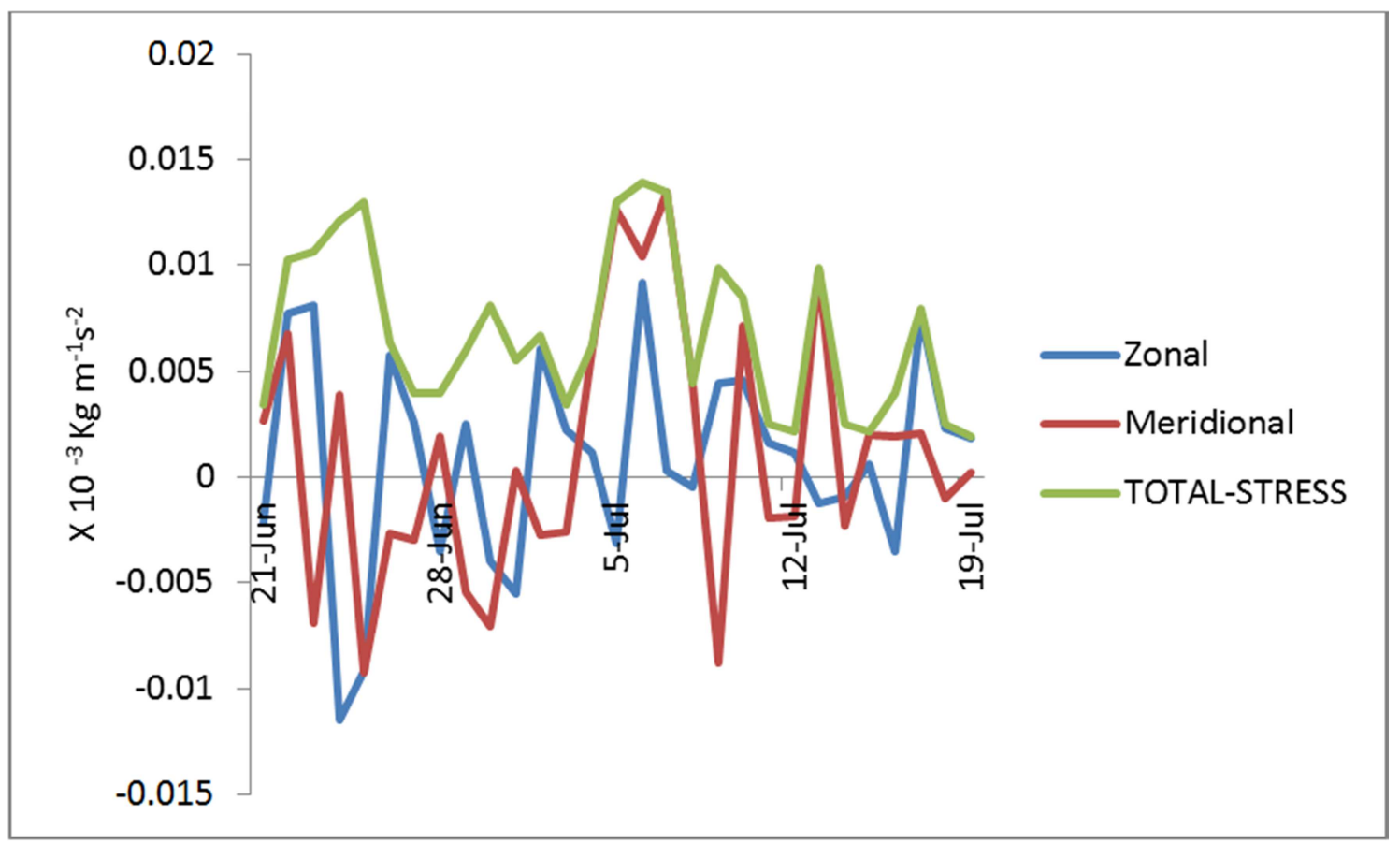

Fig. 2. Time series of wind stress components during summer survey. 


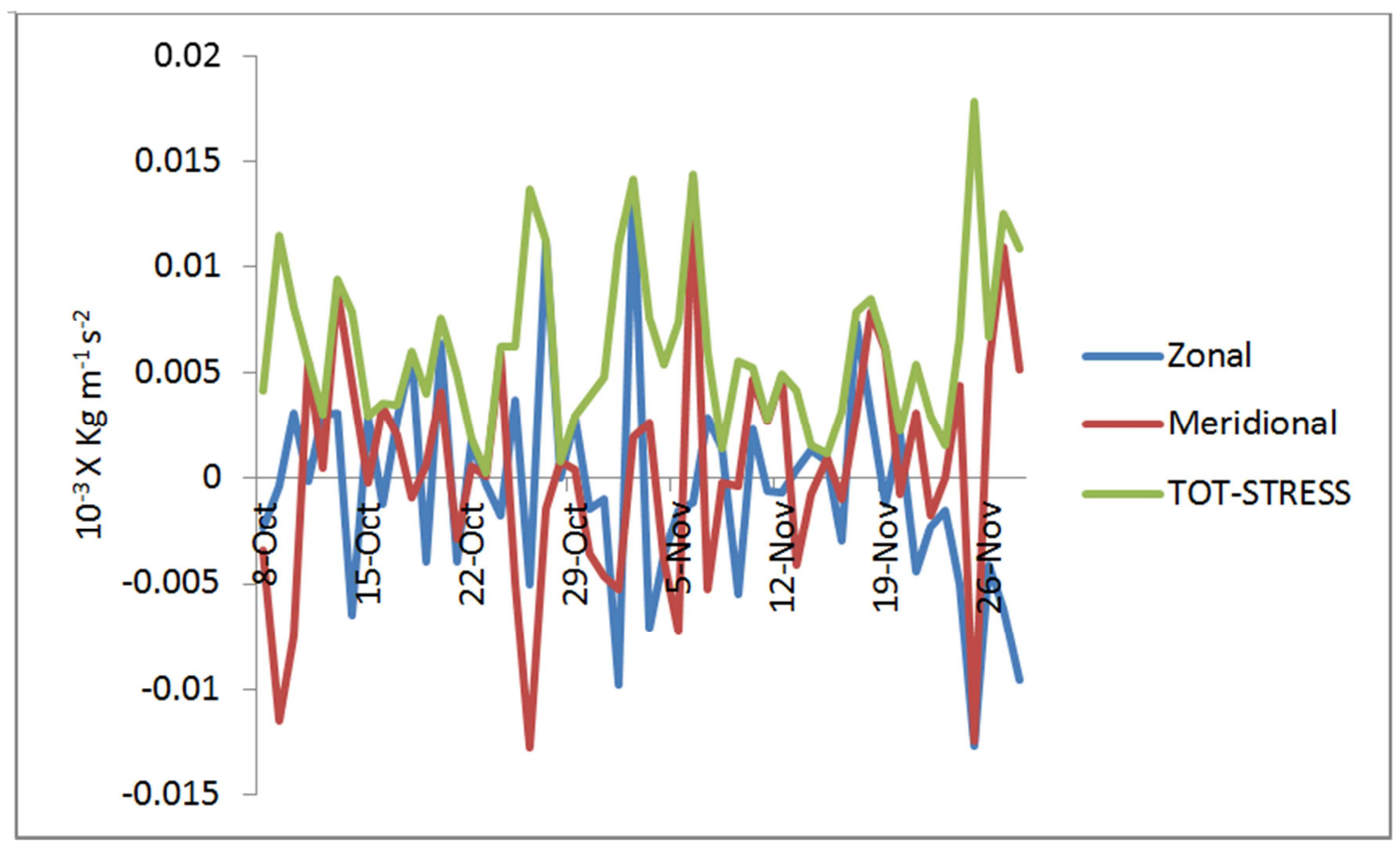

Fig. 3. Time series of wind stress components during autumn survey.

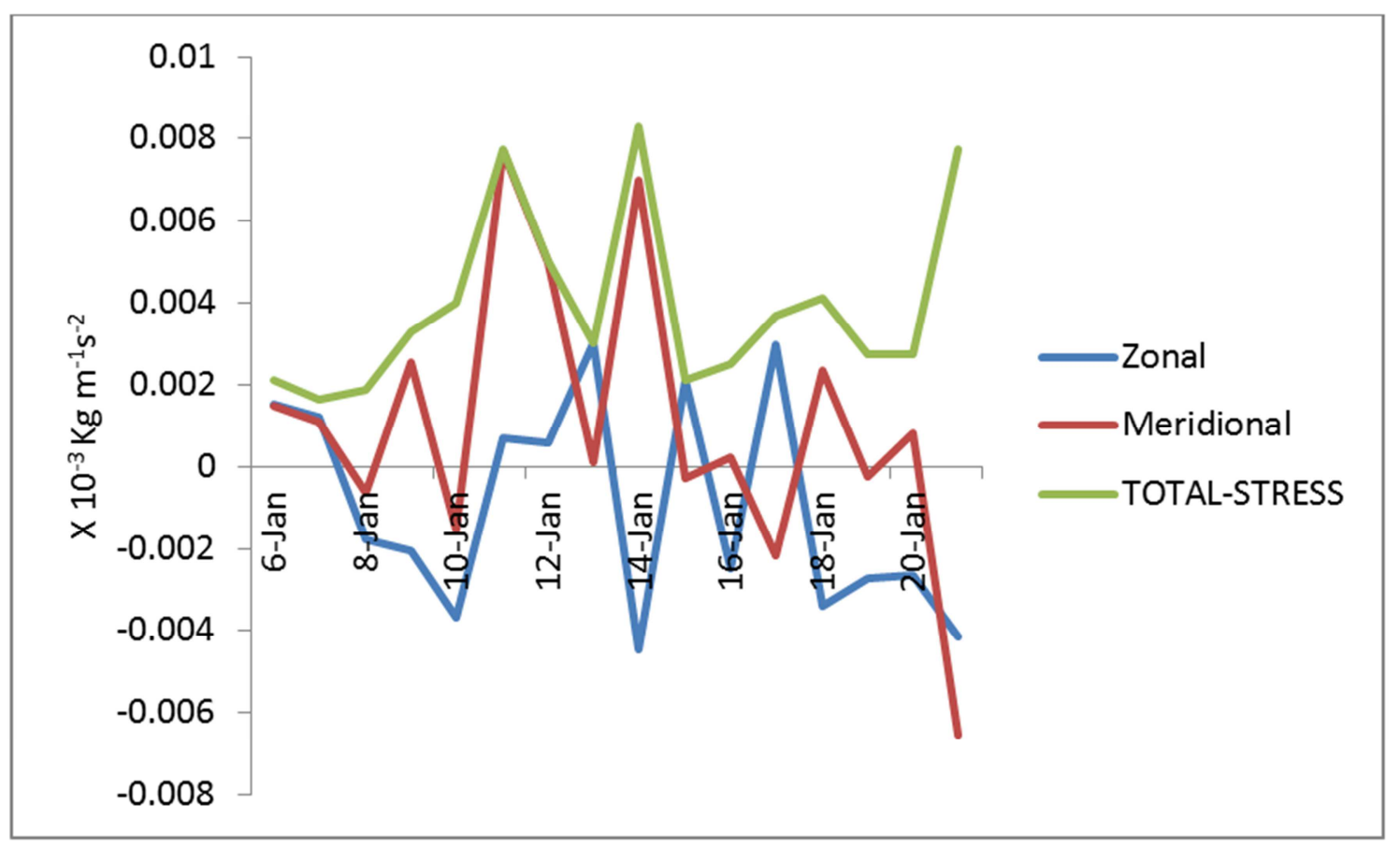

Fig. 4. Time series of wind stress components during winter survey.

\section{Estimates of Wind Contribution}

The contribution of atmospheric forcing to the dynamical process of vertical turbulent mixing is estimated by the empirical formula [10]:

$$
R u=\frac{\frac{\rho a}{\rho_{s}} W^{2}}{U_{\max }^{2}+\frac{\rho a}{\rho_{S}} W^{2}}
$$

where $U_{\max }$ is the greatest magnitude of the surface current, $\rho_{s}$ is the mean sea water density $\left(1028 \mathrm{~kg} \mathrm{~m}^{-3}\right)$. The nondimensional parameter $R u$ has values ranging from 0 to 1 , where values close to 1 indicate strong wind contribution to vertical mixing in the upper layers of the sea and vice versa.

Generally, wind contribution to vertical mixing exhibits an oscillatory behavior as shown in figures (5-8). The contribution of wind stress over the sea surface in vertical mixing production is greatest during summer. This is most probably a result of the meteorological fact that mean wind stress is greatest during summer due to the north westerly 
prevailing wind. Values of $R u$ attain the maximum at 0.6, with a mean value of 0.3 , while wind contribution is weakest during winter with a maximum value of $R u=0.2$, and mean value of $R u=0.1$. Statistically, autumn and summer have similar characteristics as wind contribution varies from zero to 0.5 , with a mean value of 0.2 .

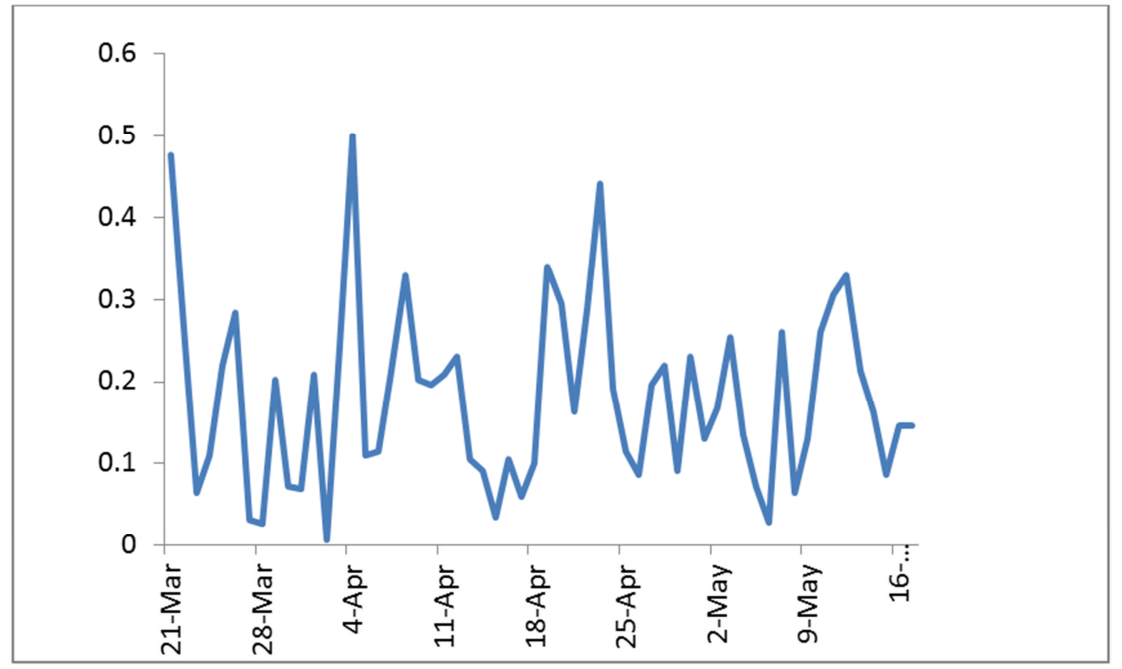

Fig. 5. Time series of wind contribution during spring survey.

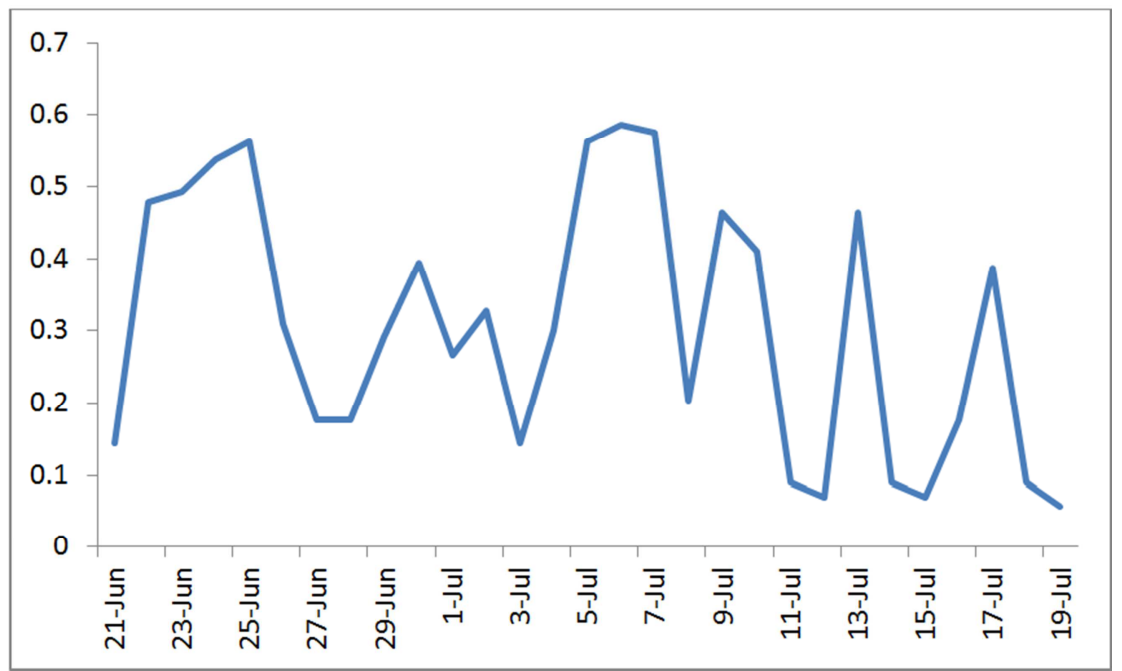

Fig. 6. Time series of wind contribution during summer survey.

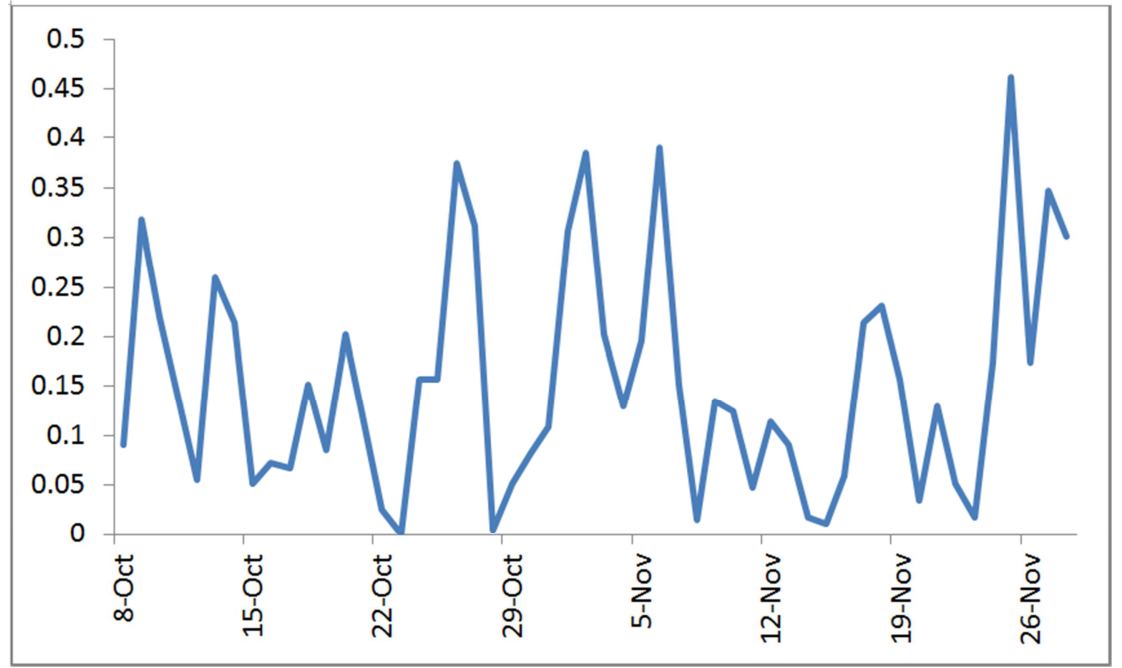

Fig. 7. Time series of wind contribution during autumn survey. 


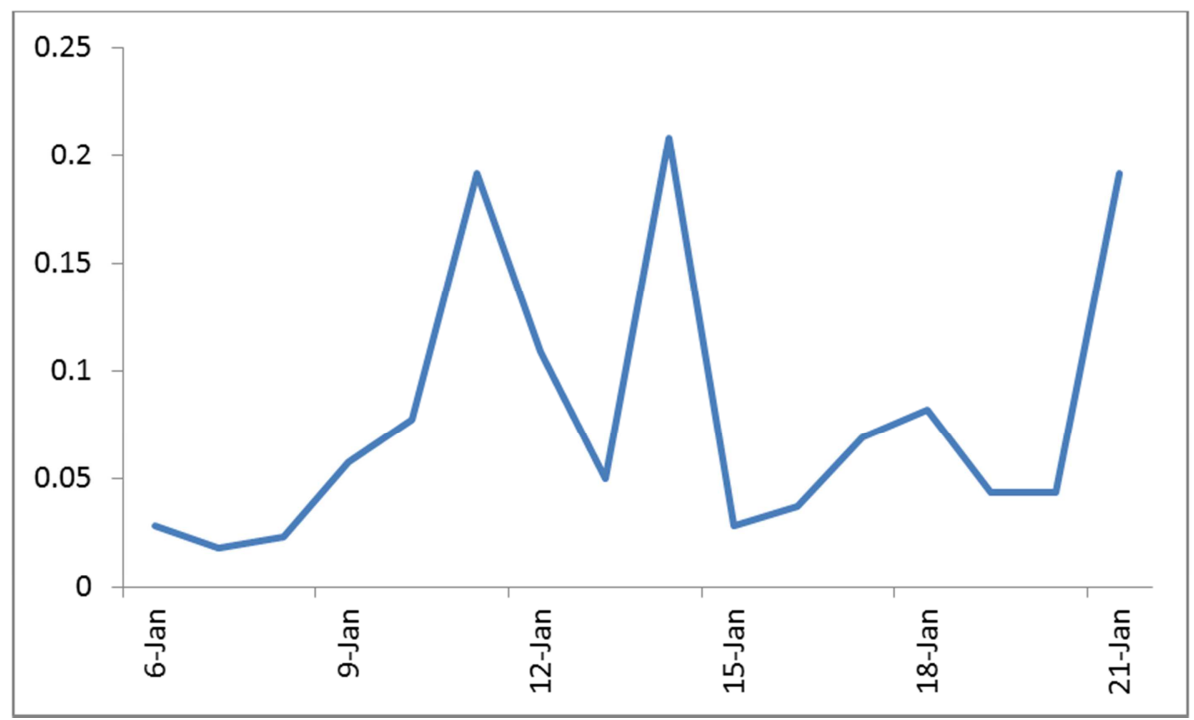

Fig. 8. Time series of wind contribution during winter survey.

Table 2. Basic statistics for the index of wind contribution to vertical mixing (Ru).

\begin{tabular}{lll}
\hline & Mean & Range \\
\hline Spring & 0.2 & $0-0.5$ \\
Summer & 0.3 & $0.1-0.6$ \\
Autumn & 0.2 & $0-0.5$ \\
Winter & 0.1 & $0-0.2$ \\
\hline
\end{tabular}

\section{Conclusions}

Generally, wind stress played a significant role in the turbulent process of vertical mixing over most of the year. Winter was an exception, and atmospheric forcing had a small role in vertical turbulent mixing as $R u$ never exceeded 0.2 , and had a mean value of 0.1 . The small tidal range at Port Said (less than $1 \mathrm{~m}$ ) produced an insignificant role for tidal forcing, particularly, at a deep offshore station. In conclusion, wind was a significant factor, besides surface wave breaking and tidal forcing, in the production of vertical mixing in the near surface layers off Port Said. Further studies with longer durations, and more sampling stations are needed for a comprehensive understanding of the role of atmospheric forcing over the sea surface in production of vertical mixing.

\section{Acknowledgements}

I express my appreciation to the National Institute of Oceanography and Fisheries, Egypt for providing research facilities. Also, I thank Dr. Ahmed Radwan for his valuable help.

\section{References}

[1] Lien, R. C., Greg, M. C., Observations of turbulence in a tidal beam and across a coastal ridge. Jour. Geophys. Res., vol. 106 , pp. 4575-4591. 2001.
[2] Munka, W, Wunschb, C., Abysal Recipes II: Energetics of tidal and wind mixing, Jour. Deep sea Res., part 1, 45(12), pp. 1977-2010, 1998.

[3] Lee, H-C, Rosati, A., Spelman, M. J., Barotropic tidal mixing effects in a coupled climate model: Oceanic conditions in the Northern Atlantic, Ocean modeling, vol. 11, pp. 464477.2006.

[4] Ly, L. N., Garwood, R. W., Numerical modeling of wave enhanced turbulence in the oceanic upper layer, Jour. Phys. Ocean., Vol. 56, pp. 473-483.2000.

[5] Sharaf El-Din, S. H., Eid, F. M., Saad, N. N., Alam El-Din, K. A., Elsharkawy, M. S., A numerical study of turbulent mixing parameters at the nile delta, north of the egyptian coast. Inter. Jour. Bio. Cons. Vol. 2 (12), pp. 422-428. 2010.

[6] Saad, N. N., Elsharkawy, M. S., Evaluation of some dynamical parameters at the central red sea during early summer. JKAU: Mar. Sci., vol. 21(1), pp. 115-122, 2010. DOI: 10. 4197/Mar. 21-1.6.

[7] Sharaf El-Din, S. H., Eid, F. M., Saad, N. N., Alam El-Din, K. A., Elsharkawy, M. S., Variation of turbulent mixing parameters at the Egyptian Mediterranean Coast. Inter. Jour. Bio. Cons. Vol. 2 (5), pp. 114-129. 2010.

[8] Hellerman, S., Rosentein, M., Normal wind stress over the world ocean with error estimates. Jour. Phys. Ocean. Vol. 13, pp. 1093-1104. 1983.

[9] Said, M. A., Variations of current, wind and water fluxes in the south -eastern Mediterranean off the Egyptian Coast during winter and spring seasons. Mahasagar, Vol. 27 (1), pp. 1-16.1994.

[10] Verspecht, F., Rippeth, T., Howrath, M., Souza, A., Simpson, J., Burchard, H., Processes impacting on stratification in a region of fresh water influence: application to Liverpool Bay, Jour. Geophys. Res. vol. 114, pp. 1-12. 2009. 